\title{
Informational content, literacy demands, and usability of websites offering health-related genetic tests directly to consumers
}

\author{
Christina R. Lachance, MPH ${ }^{1}$, Lori A. H. Erby, PhD, CGC ${ }^{2}$, Beth M. Ford, ScM ${ }^{1}$, \\ Vincent C. Allen, Jr., BA ${ }^{1}$, and Kimberly A. Kaphingst, ScD ${ }^{1}$
}

\begin{abstract}
Purpose: As direct-to-consumer genetic testing becomes more available, a diverse group of consumers, including those with limited health literacy, may consider testing. In light of concerns raised about directto-consumer genetic testing, this study sought to critically examine whether the informational content, literacy demands, and usability of health-related direct-to-consumer websites met existing recommendations. Methods: A content analysis was performed on 29 health-related direct-to-consumer websites. Two coders independently evaluated each website for informational content (e.g., benefits, limitations), literacy demands (e.g., reading level), and usability (e.g., ease of navigation). Results: Most sites presented health conditions and some markers for which they tested, benefits of testing, a description of the testing process, and their privacy policy. Fewer cited scientific literature, explained test limitations, or provided an opportunity to consult a health professional. Key informational content was difficult to locate on most sites. Few sites gave sample disease risk estimates or used common language and explained technical terms consistently. Average reading level was grade 15. Conclusion: The quality of informational content, literacy demands, and usability across health-related direct-to-consumer websites varied widely. Many users would struggle to find and understand the important information. For consumers to better understand the content on these sites and evaluate the meaning of the tests for their health, sites should lower the demands placed on users by distilling and prioritizing the key informational content while simultaneously attending to the reading level and usability elements. In the absence of regulation compelling such changes, government agencies or professional organizations may need to increase consumer and provider awareness of these issues. Genet Med 2010:12(5):304-312.
\end{abstract}

Key Words: direct-to-consumer, genetic testing, Internet, health literacy, usability

Since the completion of the human genome project in 2003, $\checkmark$ there has been much discussion of a new era of personalized medicine that will transform both healthcare and the way we

From the ${ }^{1}$ Social and Behavioral Research Branch, National Human Genome Research Institute, National Institutes of Health, Bethesda, Maryland; and ${ }^{2}$ Department of Health, Behavior and Society, Johns Hopkins Bloomberg School of Public Health, Baltimore, Maryland.

Kimberly A. Kaphingst, ScD, Health Communication Research Laboratory, 700 Rosedale Ave, Campus Box 1009, St. Louis, MO 63112-1408. E-mail: kkaphingst@gwbmail.wustl.edu.

Supplemental digital content is available for this article. Direct URL citations appear in the printed text and are available in the HTML and PDF versions of this article on the journal's Web site (www.geneticsinmedicine.org).

Disclosure: The authors declare no conflicts of interest.

Submitted for publication December 7, 2009.

Accepted for publication March 2, 2010.

Published online ahead of print April 8, 2010

DOI: 10.1097/GIM.0b013e3181dbd8b2 interact with our genetic information. ${ }^{1-3}$ Although the promise that genomics will revolutionize modern medicine is likely still some years off in the future, another revolution has taken place outside the doctor's office: the promotion and sale direct-toconsumer (DTC) of health-related genetic tests over the internet. Today, anyone with an internet connection and a credit card can purchase online a wide number of health-related genetic tests from companies who claim it will give them not only insight into their genomes but also information about future disease risk that will enable them to better make important life decisions. The number of companies offering DTC genetic testing has grown rapidly along with coverage of the phenomenon in both the mainstream and scientific media, and recent data have shown that awareness of this type of testing is relatively high both among consumers and providers. ${ }^{4,5}$

DTC companies offer various types of genetic tests, including whole genome sequencing, single nucleotide polymorphism (SNP)-based tests for susceptibility to complex, multifactorial diseases, and tests for known mutations in disease-associated genes. In addition to genetic results, some companies suggest behavioral, dietary, and other lifestyle changes that consumers can make to decrease their risk of disease. Some of the more prominent companies have made claims that DTC testing not only educates the public about genetics and disease risk but also democratizes access to health information, because there is no doctor's visit involved. ${ }^{6}$ These companies use empowerment rhetoric that encourages consumers to take control of their health by accessing their genetic information. ${ }^{7}$

In response to these companies, a number of professional associations and academics in public health and genetics have vocally criticized the clinical utility and validity of many DTC genetic tests and caution against their use for health-related purposes. ${ }^{8}$ Such experts assert that current tests being offered have not been validated in diverse populations and that more research is needed before these tests are used by consumers. ${ }^{8,9}$ Many researchers have also raised concerns about consumers interpreting complex genetic information without the involvement of a healthcare provider who has specialized knowledge of genetics, given the potential for misinterpretation of disease risks. ${ }^{8,10-12}$

One group of consumers who has been overlooked in the current debate about the potential of DTC genetic testing to inform and empower is that of adults with limited genetic literacy. As the cost of sequencing continues to decrease and DTC companies lower the price of their services, DTC genetic testing is becoming increasingly affordable and accessible to broader segments of the population. More than one-third of US adults have limited health literacy, ${ }^{13}$ and many more are likely to have limited genetic literacy. ${ }^{14}$ Previous research has shown that even those with high educational attainment have difficulty understanding the probabilistic information that is characteristic of genetic information. ${ }^{14}$ In addition, although adults may have some familiarity with genetics-related terms, they are unlikely 
to understand fully the underlying concepts. ${ }^{14-17}$ Therefore, because DTC genetic tests are becoming increasingly accessible, because the Internet is an important health information source for consumers, ${ }^{13}$ and because internet use is increasing in every demographic group including among those likely to have limited literacy, ${ }^{18}$ it is important to examine whether DTC companies present web-based information that can be understood and used by consumers with a range of health literacy skills. One way to assess the appropriateness of such information is to examine the content, reading level, and usability of DTC websites.

\section{Guidelines for content}

Guidelines and recommendations that have been issued by various professional organizations are one standard for assessing the content of DTC websites. In the United States, a number of professional associations (e.g., American Society of Human Genetics, American College of Medical Genetics, American College of Clinical Pharmacology) have developed guidelines that seek to establish standards for the responsible provision of DTC genetic testing services. These bodies recommend that companies offering health-related DTC genetic testing provide information regarding test validity and the current limitations of the science, disclose the risks and benefits of undergoing testing, use Clinical Laboratory Improvement Amendments (CLIA)-certified laboratories, carefully maintain the privacy of consumers' information, disclose the clinical evidence for behavior change recommendations, and involve a health professional in the testing process. $9,20,21$

In addition, health literacy experts have created guidelines for the design of health-related materials to improve their reading level and increase their usability by adults with varying health literacy skills. These recommendations describe optimal strategies for organization, writing style, and layout of health information. ${ }^{21}$ One widely used tool, the Suitability Assessment of Materials, includes an objective rating scale designed to assess the quality of a material's informational content, reading level, writing style, sentence construction, use of vocabulary, graphics, organizational cues (e.g., headers, captions), typography, and layout. ${ }^{21}$ Similarly, web usability experts have issued user-centered guidelines for optimizing online health information. ${ }^{22}$ For example, they recommend the use of navigational elements (e.g., ensuring each page has a unique title, using visual cueing devices such as boxes and arrows to direct attention) that help users easily move through a website and an organizational structure that prominently places the most important information on a page. 22,23

Recent research on DTC genetic testing has predominantly focused on its ethical and policy implications and its potential impact on consumers. ${ }^{24-28}$ No study to date has examined the features of DTC genetic testing websites in light of health literacy considerations. The primary objectives of this study were therefore to assess the informational content, literacy demands, and usability of health-related websites offering genetic testing DTC. We critically examined these websites to assess whether the content met existing guidelines for information, health literacy, and web usability.

\section{METHODS}

\section{Site selection}

In this analysis, we examined websites in which consumers could directly purchase and receive genetic testing without the mandatory involvement of a healthcare provider. We focused only on tests related to health conditions or diseases, and therefore we excluded any websites or portions of websites offering testing exclusively for paternity, ancestry, and/or pharmacogenomics. We also excluded websites that used genetic information solely for the purposes of providing advice on nutritional or behavior-related lifestyle choices without identifying a specific health risk.

We identified DTC websites for this analysis using two methods. First, we consulted a list of DTC companies prepared by the Genetics and Public Policy Center (version date November 23, 2008). ${ }^{29}$ Three of the 32 companies on the list were excluded because they did not test for health conditions (e.g., testing for athletic performance, fetal gender). Second, two of the authors independently conducted comprehensive web searches for additional DTC genetic testing websites using four popular search engines (Google.com, Ask.com, Altavista.com, and MSN Live Search) and one meta-search engine (Metacrawler.com). Adapting keywords used by Gollust et al., ${ }^{30}$ the following search terms were used: "genetics OR DNA + test OR testing + home OR kit OR disease," "direct to consumer genetic OR gene + testing company," "ordering a DNA/ genetic test online," "personal genome service," "online genetic testing," "my DNA," "learning about my genes," and "my genome." Valid DTC genetic testing company URLs appearing within the first 30 search results were considered for inclusion in the sample. ${ }^{22}$ The comprehensive web search identified one additional health-related DTC genetic testing website. One website was excluded because of its high degree of overlap with another website in the sample, therefore 29 websites were included in the analysis.

\section{Codebook development}

The codebook for analysis was based on the informational content, health literacy, and usability criteria described above, in addition to previous health literacy-related content analysis research. ${ }^{31}$ The complete coding dimensions are presented in the Technical Appendix, Supplemental Digital Content 1, http://links.lww.com/GIM/A103. Coding dimensions were grouped into two domains. Group 1 contained items evaluating the key informational content of the websites (e.g., health conditions, markers, testing process, scientific evidence, benefits, limitations, involvement of healthcare providers, privacy). These coding dimensions were based on the recommendations set forth by the professional associations regarding the key pieces of information that should appear on DTC genetic testing websites. Group 2 contained items evaluating the literacy and usability demands of the websites. For the literacy demand (i.e., level of health literacy required to use the sites) and usability domains (e.g., ease of locating the informational content, text density, navigational cues, layout and format, table structure), coders were asked to base their assessments on the sections of the website that contained the key informational content defined in the Group 1 domains. Coding dimensions for ease of location (e.g., evaluation of whether the content was displayed on the homepage, second-level page, or lower-level page) were adapted from published measures by the research team. These adapted dimensions used an objective predefined formula, based on page level and prominence of content, which the coders then referenced to determine the ease or difficulty of locating key content. Literacy demands were assessed using the Simple Measure of Gobbledygook (SMOG) and Fry readability formulas, as described below. Three trained independent coders refined the codebook in two rounds of pilot testing using DTC websites that had been excluded from the main sample (e.g., ancestry sites). 


\section{Coding and analysis}

From March through June 2009, two coders independently coded each of the websites in the study sample and discussed any discrepant scores to achieve consensus. Sites were coded in a predetermined order; the coders completed coding a given site within 3 to 5 days of each other. We conducted the analysis of the close-ended items based on the consensus codes using SPSS 15.0 for Windows (Chicago, IL). Percent agreement was calculated for close-ended codes. The following variables did not meet the preestablished threshold of $70 \%$ agreement between coders: description of DNA sample collection (59\%) and analysis $(59 \%)$; ease of locating stated benefits $(69 \%)$, limitations $(62 \%)$, and information about the involvement of healthcare providers $(66 \%)$; description of privacy policy $(69 \%)$; website purpose $(66 \%)$; and relevance of content to making a health decision $(69 \%)$. Because the level of agreement was, in most cases, close to $70 \%$ and because of their central importance as key content variables according to the recommendations of the professional associations, we present data on these items below, with appropriate notations regarding their reliability.

We assessed the readability of each website using two formulas: the SMOG and the Fry. The SMOG readability formula yields grade-level estimates of reading difficulty based on the number of words with three or more syllables in a sample of 30 sentences. ${ }^{32}$ The Fry formula measures sentences per 100 words and syllables per 100 words and plots the approximate reading grade level on a graph. ${ }^{33}$ To perform the readability assessment, coders independently sampled three passages of text from three different key content areas on the website based on the same priority ordering: home page, health conditions, markers, testing process, benefits, limitations, involvement of healthcare provider, and privacy. Each coder then calculated both an average SMOG and an average Fry readability score independently for each site, and the scores from each coder were averaged to create a consensus score for each readability formula. Using a scoring tolerance of within two grade levels, coders achieved $76 \%$ agreement on the Fry and $83 \%$ agreement on the SMOG.

\section{RESULTS}

\section{Test type offered}

Given that the sites varied both in their purpose and in the type of testing they offered, it would be expected that the information presented on the sites relating to the benefits and limitations of the tests would vary accordingly. We therefore grouped the sites according to the type of testing they offered, breaking them down into three main types: whole genome sequencing or whole genome scans (7 sites), tests for one or more SNPs (15 sites), and tests for known gene mutations (e.g., cystic fibrosis, hemochromatosis) (7 sites). Four sites offered tests encompassing more than one type; these were grouped according to the type of test they offered most frequently.

Across the three main types of tests, the websites offered testing for a wide range of health-related conditions and diseases; in total, 255 health conditions and traits representing 20 different categories (Table 1). Websites varied in terms of the categories of conditions for which tests were offered; some offered tests from only one category, and another offered tests from 18 of the categories. On average, websites in our sample offered tests from four different categories of conditions. The most frequently offered genetic tests included those for cardiovascular disease risk and those related to metabolism of or response to pharmaceuticals or other substances. Several categories of genetic tests (tests for susceptibility to diseases of the urinary or immune systems, skin diseases, and risks related to infectious disease) were only sold on sites that also offered tests from at least five other condition categories. Otherwise, there were few discernible patterns to the categories of testing offered by the included sites.

\section{Website content}

The key informational content of these health-related DTC genetic testing websites is described in Table 2. Almost all $(97 \%)$ of the websites listed at least one of the health conditions for which they offered testing and 79\% listed at least one of the tested markers (SNPs). Results for these two items did not vary substantially according to the type of test offered on the website. About one-third of sites (38\%) provided scientific evidence to support the tested markers and $21 \%$ cited specific scientific publications to support marker selection, although this varied substantially by type of website. Twenty-one percent of sites explained how they calculated the risk estimates given to consumers in their test results; this was most commonly done by the whole genome sites $(43 \%)$.

For the testing process, almost all (93\%) of the sites gave at least a brief description of the process by which the consumer's DNA sample is collected and three-quarters (76\%) at least briefly described how the sample is analyzed. About one-half $(45 \%)$ of sites stated that they used a CLIA-certified laboratory to analyze the DNA samples. Only 14\% of sites provided an opportunity for consumers to consult with a healthcare provider before testing, whereas $28 \%$ provided that opportunity after testing; this was most common among sites offering tests for known mutations. Less than one-quarter (21\%) of sites gave information for healthcare providers about how they could interpret and use a patient's DTC genetic test results.

In terms of privacy, $79 \%$ of sites gave some information about their privacy policy. Two-thirds $(65 \%)$ provided information on the people behind the company, although only $24 \%$ clearly identified any scientific collaborators and described their access to consumers' DNA samples.

\section{Benefits}

Almost all of the sites (90\%) listed at least one benefit to consumers of undergoing testing, although this was less common among sites offering testing for known mutations (57\%). Of those sites that stated a benefit, the one most frequently stated $(76 \%)$ was that the results of a test can inform a health decision (data not shown). Other commonly stated benefits were that there would be a benefit to the consumer in the future (35\%); being tested could be beneficial to one's family or children (24\%); information itself is beneficial (24\%); and there would be a benefit to scientific research $(21 \%)$.

\section{Limitations}

About one-half $(55 \%)$ of the sites overall presented at least one limitation related to undergoing testing, although all $(100 \%)$ of the whole genome sites listed limitations. Of those sites that stated a limitation, the limitations most frequently stated were that other factors are important for disease risk (45\%); the science surrounding testing is still uncertain (17\%); the tests cannot diagnose diseases (14\%); and testing was provided for only a limited number of mutations (14\%; data not shown). About one-third (34\%) of sites offered some mechanism to allow consumers to receive updated information over time. About one-half of the sites $(45 \%)$ stated that the science underlying the tests is new and/or changing, although this was often not described as a limitation of the test. 
Table 1 Categories of health conditions for which sites offered testing

\begin{tabular}{|c|c|c|}
\hline Category & Examples of conditions & Sites selling tests $(N=29)^{a}$ \\
\hline Chromosome analysis/fluorescence in situ hybridization & Recurrent pregnancy loss, 22q deletion & $2(7)$ \\
\hline Single gene diseases & Cystic fibrosis, hemochromatosis & $7(24)$ \\
\hline \multicolumn{3}{|l|}{ Cancer susceptibility } \\
\hline High penetrance & BRCA1/2, PTEN & $3(10)$ \\
\hline Low penetrance & Lung cancer, prostate cancer & $7(24)$ \\
\hline \multicolumn{3}{|l|}{$\begin{array}{l}\text { Susceptibility to noncancerous common complex } \\
\text { diseases }\end{array}$} \\
\hline Cardiovascular & Cardiovascular disease, thrombosis & $15(52)$ \\
\hline Digestive & Crohn's disease, gallbladder disease & $8(28)$ \\
\hline Endocrine & Obesity, type 2 diabetes & $6(21)$ \\
\hline Immune & Allergies, lupus & $6(21)$ \\
\hline Nervous & Amyotrophic lateral sclerosis, epilepsy & $10(34)$ \\
\hline Reproductive & Endometriosis, infertility & $4(14)$ \\
\hline Respiratory & Asthma, emphysema & $4(14)$ \\
\hline Skeletal & Arthritis, back pain & $9(31)$ \\
\hline Skin & Psoriasis & $3(10)$ \\
\hline Urinary & Kidney stones & $2(7)$ \\
\hline Susceptibility to psychiatric conditions & Depression, schizophrenia & $4(14)$ \\
\hline Risk due to oxidative stress & Coenzyme Q10 efficiency, oxidative stress & $3(10)$ \\
\hline $\begin{array}{l}\text { Metabolism of or response to pharmaceuticals } \\
\text { or other substances }\end{array}$ & Caffeine metabolism, $\beta$ blocker response & $13(45)$ \\
\hline Substance dependence & Nicotine dependence, heroin addiction & $4(14)$ \\
\hline Infectious disease risk or progression & HIV progression, norovirus resistance & $3(10)$ \\
\hline Nondisease-related health profiles & Fatigue, body composition & $9(31)$ \\
\hline
\end{tabular}

\section{Literacy and usability}

The results for the health literacy and usability criteria are shown in Tables 3 and 4 .

\section{Ease of location}

We assessed how easy it was to locate information about each of the informational content topics on the websites (see Table 3). Overall, information about health conditions was easy to locate on $62 \%$ of the websites, although this varied greatly by type of site. In contrast, information about tested markers was easy to locate on only $17 \%$ of sites. Information regarding benefits was easy to locate on $41 \%$ of sites, although this was notably lower among sites offering testing for known mutations (14\%). Information regarding limitations was easy to locate on only $14 \%$ of sites. Privacy information was easy to locate for just less than one-half of the sites $(48 \%)$, although this was higher among sites offering testing for known mutations (71\%).

\section{Additional literacy and usability dimensions}

For organizational criteria (Table 4), 59\% of the sites explicitly stated their purpose on the home page. In $41 \%$ of the sites, more than one-half of the content related to key informational content, although this varied greatly across website type. About one-fourth $(28 \%)$ of sites gave pretest risk estimates for at least one disease and this was most common among the whole genome sites $(57 \%)$

In assessing the literacy demand of the sites, very few (7\%) used mostly common language and consistently explained technical terms. About one-half (52\%) used mostly active voice and $31 \%$ used mostly simple sentences, although this varied across site type. The sites had a very high level of reading difficulty. The mean SMOG score was 14.7 (range, 12-18) and the mean Fry score was 15.2 (range, 10.5-17), which can be interpreted as the sites required college-level reading skills, on average.

For the graphics and visuals used on the sites, in about one-half of the sites $(48 \%)$, these were used in ways that supported the main content; this was highest among the whole genome and known mutation sites $(71 \%)$. A majority of the sites $(62 \%)$ had at least brief captions explaining graphics, although this was less common among the SNP-based sites (47\%). However, on only about one-third of the sites (34\%) did graphics consistently portray familiar objects. A majority of sites $(83 \%)$ used relatively simple tables.

For learning stimulation and motivation, only about one-third of the sites (34\%) provided a glossary to assist users with technical terms. Forty-one percent provided a tutorial; this was 
Table 2 Content characteristics of health-related DTC genetic testing websites

\begin{tabular}{|c|c|c|c|c|}
\hline Content item & $\begin{array}{l}\text { Overall } \\
(N=29)\end{array}$ & $\begin{array}{l}\text { Whole genome } \\
\qquad(N=7)\end{array}$ & $\begin{array}{l}\text { SNP-based tests } \\
\quad(N=15)\end{array}$ & $\begin{array}{l}\text { Known mutations } \\
\quad(N=7)\end{array}$ \\
\hline Listed one or more health conditions & $28(97)$ & $6(86)$ & $15(100)$ & $7(100)$ \\
\hline Listed one or more tested markers & $23(79)$ & $5(71)$ & $12(80)$ & $6(86)$ \\
\hline $\begin{array}{l}\text { Provided scientific evidence or data to } \\
\text { support marker selection }\end{array}$ & $11(38)$ & $2(29)$ & $8(53)$ & $1(14)$ \\
\hline $\begin{array}{l}\text { Cited specific publications to support } \\
\text { marker selection }\end{array}$ & $6(21)$ & $3(43)$ & $2(13)$ & $1(14)$ \\
\hline $\begin{array}{l}\text { Explained how risk is estimated/calculated } \\
\text { risk }\end{array}$ & $6(21)$ & $3(43)$ & $2(13)$ & $1(14)$ \\
\hline Described how the DNA sample is collected ${ }^{a}$ & $27(93)$ & $6(86)$ & $14(93)$ & $7(100)$ \\
\hline Described how the DNA sample is analyzed ${ }^{a}$ & $22(76)$ & $6(86)$ & $10(67)$ & $6(86)$ \\
\hline Stated use of a CLIA-certified laboratory & $13(45)$ & $4(57)$ & $7(47)$ & $2(29)$ \\
\hline \multicolumn{5}{|l|}{$\begin{array}{l}\text { Provided an opportunity to talk to a healthcare } \\
\text { provider }\end{array}$} \\
\hline Before testing & $4(14)$ & $1(14)$ & $1(7)$ & $2(29)$ \\
\hline After testing & $8(28)$ & $2(29)$ & $3(20)$ & $3(43)$ \\
\hline $\begin{array}{l}\text { Explained to providers how to interpret/use } \\
\text { test results }\end{array}$ & $6(21)$ & $2(29)$ & $3(20)$ & $1(14)$ \\
\hline $\begin{array}{l}\text { Mentioned privacy or provided privacy } \\
\text { policy }^{a}\end{array}$ & $23(79)$ & $6(86)$ & $11(73)$ & $6(86)$ \\
\hline Identified people behind the company & $19(65)$ & $5(71)$ & $10(67)$ & $4(57)$ \\
\hline $\begin{array}{l}\text { Identified scientific collaborators but role not } \\
\text { stated }\end{array}$ & $7(24)$ & $3(43)$ & $2(13)$ & $2(29)$ \\
\hline Listed at least one benefit related to testing & $26(90)$ & $7(100)$ & $15(100)$ & $4(57)$ \\
\hline $\begin{array}{l}\text { Listed at least one limitation related to } \\
\text { testing }\end{array}$ & $16(55)$ & $7(100)$ & $6(40)$ & $3(43)$ \\
\hline $\begin{array}{l}\text { Offered a mechanism for updates on test } \\
\text { results }\end{array}$ & $10(34)$ & $6(86)$ & $2(13)$ & $2(29)$ \\
\hline Stated that the science is new or changing & $13(45)$ & $6(86)$ & $4(27)$ & $3(43)$ \\
\hline
\end{tabular}

most common among the whole genome sites (71\%). About one-third of sites $(34 \%)$ provided a search engine to assist web navigation. Most (93\%) displayed a link to the home page from second level pages, and many (59\%) displayed a link to the home page from third level pages (data not shown).

\section{DISCUSSION}

In this content analysis, we observed a wide range in the quality of informational content in addition to the literacy demands and usability, across health-related DTC genetic testing websites. Although guidelines for these areas have been widely published, they have been variably adopted in the design of these websites. It is further apparent that most users would struggle to find and understand the important information on most sites. Therefore, our findings provide empirical evidence for many of the recent critiques of DTC genetic testing websites, although they also lend some support to arguments that websites offering different types of genetic tests should not be lumped together in assessments of their content and quality.

\section{Content findings}

Overall, most sites presented health conditions and at least some markers for which they offered testing, described their process of collecting and analyzing DNA samples, and stated their privacy policy. Privacy policies were often filled with jargon and, although most sites identified the people who ran the company, there was far less transparency regarding the role of scientific collaborators (whether academic or private industry). The standard of clearly describing which collaborators would have access to consumer data at which points in the testing process and their relationship to the testing company was largely unmet. As described above, the recommendations from professional bodies are for consumer privacy policies to be clearly stated and for consumer data to be highly guarded. This is clearly an area in need of improvement. 
Table 3 Percentage of health-related DTC websites on which key informational content was easy to locate

\begin{tabular}{lcccc}
\hline Item & $\begin{array}{c}\text { Overall } \\
(N=29)\end{array}$ & $\begin{array}{c}\text { Whole } \\
\text { genome } \\
(N=7)\end{array}$ & $\begin{array}{c}\text { SNP-based } \\
\text { tests } \\
(N=15)\end{array}$ & $\begin{array}{c}\text { Known } \\
\text { mutations } \\
(N=7)\end{array}$ \\
\hline $\begin{array}{l}\text { Tested health } \\
\text { conditions }\end{array}$ & $18(62)$ & $2(29)$ & $10(67)$ & $6(86)$ \\
$\begin{array}{l}\text { Tested markers } \\
\text { Information } \\
\text { regarding } \\
\text { benefits }\end{array}$ & $5(17)$ & $0(0)$ & $5(33)$ & $0(0)$ \\
$\begin{array}{l}\text { Information } \\
\text { regarding } \\
\text { limitations }\end{array}$ & $12(41)$ & $4(57)$ & $7(47)$ & $1(14)$ \\
$\begin{array}{l}\text { Information } \\
\text { regarding } \\
\text { privacy }\end{array}$ & $4(14)$ & $1(14)$ & $3(20)$ & $0(0)$ \\
$\begin{array}{l}\text { Information about } \\
\text { DNA sample } \\
\text { collection and } \\
\text { analysis }\end{array}$ & $11(38)$ & $3(43)$ & $5(33)$ & $3(43)$ \\
$\begin{array}{l}\text { Information } \\
\text { regarding the } \\
\text { involvement of } \\
\text { healthcare } \\
\text { providers }\end{array}$ & & $3(43)$ & $6(40)$ & $5(71)$ \\
$\begin{array}{l}\text { Values are represented as } N(\%) . \\
\text { Intercoder agreement for this variable fell below } 70 \% .\end{array}$ & & \\
\hline
\end{tabular}

Our finding that few sites provided scientific evidence to support the selection of the markers for which they offered testing provides empirical support to many of the previously described academic critiques of these testing services. Although data regarding clinical validity and utility are not yet available for all of the markers for which companies offered testing, to meet the recommendation of providing consumers with accurate and transparent information, efforts should be made to reveal this information when it is available and a disclosure made when such information does not exist. The absence of this information could lead consumers to weigh equally the credibility of all of the tests, when, in fact, some are more clinically valid than others.

The results also showed that there was an imbalance on most sites between the provision of benefit information and limitations. Likely, because of their promotional nature, a much greater proportion of sites described the benefits of testing than the limitations inherent to these tests and their interpretation. A recent ethical analysis of 13 DTC genetic testing sites by Berg and Fryer-Edwards ${ }^{26}$ examined whether the sites provided consumers with enough information about the risks and benefits of testing to promote informed decision-making and found, similarly, that just four sites mentioned any risks associated with their tests. Our analysis further revealed that few sites stated that the science surrounding this type of testing is still uncertain. Although the limitations of testing have been established in the scientific literature, ${ }^{34,35}$ it does not seem that consumers would learn about these limitations if they relied only on the information provided to them by the websites. Furthermore, despite a disclaimer that the information found on the sites was for informational purposes only, our analysis found that more than three-quarters $(76 \%)$ of the sites simultaneously stated that the results of the test could be used to inform a health decision. As others have noted, ${ }^{35}$ such conflicting statements are not only confusing to consumers but may affect the sites' credibility. Therefore, the findings suggest that the sites may not be providing adequate education to truly empower consumers. ${ }^{37}$

Our results also show that the companies generally do not offer much assistance at the time of testing or after testing in interpreting results. Few of the websites offered consultations with health professionals before or after testing and few provided information that could be used by the consumer's own healthcare provider in interpreting their patient's test results. This is consistent with the findings of Goddard et al. ${ }^{26}$ in their analysis of websites providing DTC testing for thrombosis, which found low adherence to professional recommendations regarding the provision of information and counseling from a healthcare provider. Furthermore, only about one-third of sites offered a mechanism for updating consumers' test results. As the science is still evolving and new discoveries are rapidly being made, the meaning of genetic test results could certainly change over time. Thus, as Shirts and Parker ${ }^{38}$ have observed, the burden of keeping up with the science may largely fall on the consumers themselves who likely do not have the skills to seek out and interpret updated information. In addition, one recent study ${ }^{39}$ found that even when risk information is updated, contradictory results might be given, which can adversely affect the lifestyle and behavioral choices that could already have been adopted by a consumer, further arguing for the importance of skilled interpretation by a health professional. Finally, these companies are very volatile in nature. In the year since our sample was identified, at least three of the sites have since disappeared from the web or have merged with other DTC companies. It is not clear either how consumers' data are protected in these circumstances or how they would be notified as to a change in the interpretation of their test results when a company no longer exists.

\section{Literacy demand and usability findings}

The results presented here identify major areas in literacy demand and usability that could be improved on the websites to enhance their usefulness. Although most websites in our sample provided information across the majority of the essential content areas, this important information was difficult to locate on many of the sites, often requiring users to navigate to third and lower level pages or scroll through lengthy PDF files. Because these websites are persuasive platforms seeking to convince a consumer to make a purchase, this selective emphasis of some information over other information may not be surprising nor may it be surprising that a substantial proportion of the provided content is unrelated to helping consumers make an informed testing decision. Although active voice was used on about one-half of the sites, common language and explanations of technical terms were not used consistently. In addition, the reading level of the sites was far above the eighth to ninth grade reading level of the average US adult. ${ }^{40}$ Although individuals with limited literacy frequently encounter substantial barriers when seeking health information on the internet, ${ }^{41,42}$ these findings indicate that the majority of consumers would have difficulty using these sites. Less than one-half of the sites used graphics in a way that would support consumers in understanding the key informational content. We had anticipated that sites would make use of tools such as glossaries, tutorials, and internal search engines because these are practical online instruments that facilitate both consumer understanding and navigation, but such assistive devices were not common. In sum, our results indicate that major changes to the literacy demands 
Table 4 Literacy demands and usability of health-related DTC genetic testing websites

\begin{tabular}{|c|c|c|c|c|}
\hline Literacy demand or usability item & $\begin{array}{c}\text { Overall } \\
(N=29)\end{array}$ & $\begin{array}{l}\text { Whole genome } \\
\qquad(N=7)\end{array}$ & $\begin{array}{l}\text { SNP-based tests } \\
\quad(N=15)\end{array}$ & $\begin{array}{l}\text { Known mutations } \\
\quad(N=7)\end{array}$ \\
\hline \multicolumn{5}{|l|}{ Organization } \\
\hline $\begin{array}{l}\text { Explicitly stated purpose of website } \\
\text { on home page }\end{array}$ & $17(59)$ & $4(57)$ & $8(53)$ & $5(71)$ \\
\hline $\begin{array}{l}\text { More than one-half of the presented } \\
\text { content was relevant to making a } \\
\text { testing decision }\end{array}$ & $12(41)$ & $5(71)$ & $3(20)$ & $4(57)$ \\
\hline $\begin{array}{l}\text { Risk estimates for at least one } \\
\text { disease were presented }\end{array}$ & $8(28)$ & $4(57)$ & $3(20)$ & $1(14)$ \\
\hline \multicolumn{5}{|l|}{ Literacy demand } \\
\hline $\begin{array}{l}\text { Mostly used common language and } \\
\text { explained technical terms }\end{array}$ & $2(7)$ & $0(0)$ & $2(13)$ & $0(0)$ \\
\hline Mostly used active voice & $15(52)$ & $4(57)$ & $6(40)$ & $5(71)$ \\
\hline $\begin{array}{l}\text { Mostly used simple sentences } \\
\text { without embedded structures }\end{array}$ & $9(31)$ & $1(14)$ & $6(40)$ & $2(29)$ \\
\hline Mean SMOG level of readability & $14.7(12-18)$ & $15(13.5-18)$ & $14.8(12-17.5)$ & $13.9(12-15)$ \\
\hline Mean Fry level of readability & $15.2(10.5-17)$ & $15.5(13-17)$ & $15.7(12-17)$ & $14(10.5-17)$ \\
\hline \multicolumn{5}{|l|}{$\begin{array}{l}\text { Graphic illustrations, lists, tables, and } \\
\text { charts }\end{array}$} \\
\hline $\begin{array}{l}\text { Used graphics (picture, video, or } \\
\text { animation) that supported the key } \\
\text { information }\end{array}$ & $14(48)$ & $5(71)$ & $4(27)$ & $5(71)$ \\
\hline $\begin{array}{l}\text { Introduced graphics with brief } \\
\text { captions }\end{array}$ & $18(62)$ & $6(86)$ & $7(47)$ & $5(71)$ \\
\hline $\begin{array}{l}\text { Graphics almost always portrayed } \\
\text { familiar, real-world objects }\end{array}$ & $10(34)$ & $2(29)$ & $5(33)$ & $3(43)$ \\
\hline Used tables with $<75$ items & $24(83)$ & $5(71)$ & $13(87)$ & $6(86)$ \\
\hline $\begin{array}{l}\text { Used tables that were not dependent } \\
\text { on information located elsewhere } \\
\text { on the site }\end{array}$ & $17(59)$ & $2(29)$ & $9(60)$ & $6(86)$ \\
\hline $\begin{array}{l}\text { Did not use unlabeled graphics as } \\
\text { clickable items }\end{array}$ & $25(86)$ & $4(57)$ & $14(93)$ & $7(100)$ \\
\hline \multicolumn{5}{|l|}{ Learning stimulation and motivation } \\
\hline Provided a glossary & $10(34)$ & $3(43)$ & $4(27)$ & $3(43)$ \\
\hline Provided one or more tutorials & $12(41)$ & $5(71)$ & $3(20)$ & $4(57)$ \\
\hline \multicolumn{5}{|l|}{ Web navigation } \\
\hline Provided a search engine & $10(34)$ & $3(43)$ & $4(27)$ & $3(43)$ \\
\hline
\end{tabular}

Values are represented as $N(\%)$, except for the readability scores, which are grade levels.

${ }^{a}$ Intercoder agreement for this variable fell below $70 \%$.

and usability of the sites would be needed to make the content understandable and usable to most US adults. A logical next step to this line of research would be to conduct more formal usability assessments with users with diverse literacy and web navigational skills.

\section{Differences across site types}

Our analysis of results by site type did not identify one type of site as being a clear leader in the field in regard to both informational content and usability, but the results did indicate substantial variability across the key content criteria. Some authors have suggested that sites offering whole genome scans are making an effort to distinguish themselves as offering a higher quality service. ${ }^{36}$ Our analysis found that while these sites scored better in certain areas (e.g., stating limitations, stating the science is changing, offering a mechanism for updates, presenting risk estimates, providing tutorials), there is still room for improvement on a number of key content variables (e.g., providing scientific evidence for marker selection, explaining how risk is estimated). 


\section{Recommendations}

The public health potential of each of the examined DTC genetic testing websites will depend on the clinical utility and validity of the test and on individuals' abilities to understand the implications of information that they receive. For consumers to make informed choices about genetic testing, they need to have access to all of the relevant information in an understandable format. The results presented here suggest the following concrete areas for improvement of health-related DTC genetic testing websites. The sites should aim to provide and distill the scientific evidence they rely on to select their markers and more clearly explain to consumers and their physicians how to interpret the meaning of their results. Furthermore, coders found that navigating the sites was often a highly complex task, and designers could do a better job of making the most important information, such as the limitations of testing, easier to locate. The sites had a very high reading level, used relatively few simple sentences, and used common language or clear explanations for technical terms inconsistently. Incorporating established plain language, clear communication, and web usability strategies across all important content areas would decrease the reading level and benefit both current and potential customers by making the information more accessible. Unlike print formats, websites are tools that lend themselves well to layering information according to different information-seeking needs and preferences. This unique feature should be used to its utmost advantage to prioritize important information and then facilitate further exploration if a consumer seeks greater detail. These types of easily implemented changes would likely enhance consumer comprehension of the content on these sites and better enable them to evaluate the meaning of these tests for their health. If implemented together, such changes would also allay some of the concerns raised by academics and could further enhance the educational, and, ultimately, the public health potential of websites offering health-related DTC genetic testing websites.

\section{Policy implications}

Because these companies are for profit rather than public health or educational entities, however, it is unlikely that they will be motivated to more fully disclose the limitations of the tests they offer or to improve the accessibility of the information on their websites for a broader range of users. Further, at least one study has shown that including more balanced risk information on a website offering DTC genetic testing for breast cancer decreased participants' intentions to purchase online testing, ${ }^{43}$ and such data would likely further disincentive companies from taking steps toward fuller disclosure. Therefore, as in the case of the Food and Drug Administration requiring pharmaceutical companies to disclose drug side effects in their advertisements, ${ }^{44}$ it is likely that change will require that a state or federal regulatory body compel DTC genetic testing companies to take the measures that we and others recommend. Currently, no such agency monitors the sale and promotion of DTC genetic tests, although there have been some efforts on the part of individual states to more closely regulate the companies who sell these tests. ${ }^{24}$ Further policy work should identify the strengths and weaknesses of the various agencies that could be called upon to implement this level of oversight.

In the absence of either regulation or voluntary change on the behalf of DTC companies, it may be necessary for government agencies, professional organizations, and others to increase public awareness, and thus informed choice, through alternative means. Recently, others have suggested that the creation of a mandatory national genetic test registry administered by an agency within the US Department of Health and Human Services would provide consumers and healthcare providers with objective information regarding the analytic validity, clinical validity, and clinical utility of all genetic tests, including genetic tests marketed and sold directly to consumers. ${ }^{45}$ If such a registry was widely recognized by the public, information contained within could appropriately supplement the marketing materials produced by the companies themselves. The guidelines used throughout our study indicate that any such resource, including the DTC websites, should simultaneously attend to the scope of educational content, reading level, and usability to optimize the chance that a consumer could make a more fully informed decision regarding whether to invest in this type of testing.

\section{Limitations}

The limitations of this study should be considered in interpreting the results. We assessed only English-language sites. We did not examine the validity of the tests being offered because our primary focus was to analyze the information being presented to consumers. The readability tools may overestimate reading difficulty when the same polysyllabic word is used frequently on a web page. Although we examined the literacy demands of the sites, we did not directly assess comprehension among consumers. Finally, because of the rapidly changing nature of the websites, our results present a snapshot of the sites at a particular time, although there has been no indication of major changes on key coding criteria subsequently.

\section{CONCLUSIONS}

DTC genetic testing sites will likely reach a consumer base who is more diverse in terms of education and socioeconomic status as the technology becomes more affordable for larger numbers of interested users. However, currently, there is no evidence that even the early adopters of these services understand the information being given to them by the sites. Future research efforts should seek to directly assess the understandability of the information presented on these websites with a diverse sample of consumers, including those with limited health or genetic literacy. There is also a need to investigate how consumers who have already purchased DTC genetic testing are using the information from their test results. Are they using it to make important health decisions, to supplement existing health and family history information or is their objective in testing simply recreational? As others have commented, 35 it will also be important for both researchers and those within DTC companies to track the lifestyle and behavior changes that consumers may be making as a result of the information they receive from these tests. If the information from tests with known clinical validity and utility can motivate people to make and sustain healthy lifestyle changes, their public health utility would be strengthened.

\section{ACKNOWLEDGMENTS}

This research was supported by the Intramural Research Program of the National Human Genome Research Institute, National Institutes of Health.

The authors thank Cristofer Price of Abt Associates for assistance with data analysis. 


\section{REFERENCES}

1. Collins FS, Green ED, Guttmacher AE, Guyer MS. A vision for the future of genomics research: a blueprint for the genomic era. Nature. 2003;422: $835-847$.

2. Guttmacher AE, Collins FS. Welcome to the genomic era. $N$ Engl J Med. 2003;349:996-998.

3. Topol EJ, Murray SS, Frazer KA. The genomics gold rush. JAMA. 2007; 298:218-221.

4. Kolor K, Liu T, St. Pierre J, Khoury MJ. Health care provider and consumer awareness, perceptions, and use of direct-to-consumer personal genomic tests, United States, 2008. Genet Med. 2009;11:595.

5. Oregon Department of Human Services. Behavioral Risk Factor Surveillance System (BRFSS). Available at: http://www.dhs.state.or.us/dhs/ph/chs/ brfs/08/genetics.pdf. Accessed January 21, 2010.

6. 23andMe. Available at: https://www.23andme.com/researchrevolution/\#. Accessed November 20, 2009.

7. Geransar R, Einsiedel E. Evaluating online direct-to-consumer marketing of genetic tests: informed choices or buyers beware? Genet Test. 2008; $12: 13-24$.

8. Hunter DJ, Khoury MJ, Drazen JM. Letting the genome out of the bottlewill we get our wish? N Engl J Med. 2008;258:105-107.

9. Hudson K, Javitt G, Burke W, Byers P; American Society of Human Genetics Social Issues Committee. ASHG statement on direct-to-consumer genetic testing in the United States. Obstet Gynecol. 2007;110:1392-1395.

10. Wasson K, Cook E, Helzlsouer KJ. Direct-to-consumer online genetic testing and the four principles: an analysis of the ethical issues. Ethics Med. 2006;22:83-91.

11. Gollust SE, Hull SC, Wilfond BS. Limitations of direct-to-consumer advertising for clinical genetic testing. JAMA. 2002;288:1762-1767.

12. Ensenauer R, Michels V, Reinke S. Genetic testing: practical, ethical, and counseling considerations. Mayo Clinic Proc. 2005;80:63-73.

13. Kutner M, Greenberg E, Jin Y, Paulsen C, White S. The health literacy of America's adults: results from the 2003 National Assessment of Adult Literacy. Washington, DC: National Center for Education Statistics; 2006.

14. Lea DH, Kaphingst KA, Bowen D, Lipkus I, Hadley DW. Communicating genetic information and genetic risk: An emerging role for health educators [published online ahead of print April 20, 2010]. Public Health Genomics. doi: $10.1159 / 000294191$

15. Lipkus IM, Samsa G, Rimer BK. General performance on a numeracy scale among highly educated samples. Med Decis Making. 2001;21:37-44.

16. Lanie AD, Jayaratne TE, Sheldon JP, et al. Exploring the public understanding of basic genetic concepts. J Genet Counsel. 2004;13:305-320.

17. Mesters I, Ausems A, De Vries H. General public's knowledge, interest and information needs related to genetic cancer: an exploratory study. Eur $J$ Cancer Prev. 2005;14:69-75

18. Horrigan J. Home Broadband Adoption. Washington, DC: Pew Internet \& American Life Project, 2006. Available at: http://www.pewinternet.org/Reports/ 2006/Home-Broadband-Adoption-2006.aspx?r=1. Accessed January 26, 2010.

19. American College of Medical Genetics Board of Directors. ACMG statement on direct-to-consumer genetic testing. Available at: www.acmg.net [www.acmg.net/StaticContent/StaticPages/DTC_Statement.pdf]. Accessed July $17,2009$.

20. Ameer B, Krivoy N. Direct-to-consumer/patient advertising of genetic testing: a position statement of the American College of Clinical Pharmacology. J Clin Pharmacol. 2009;49:886-888.

21. Doak CC, Doak LG, Root JH. Teaching patients with low literacy skills. 2nd ed. Philadelphia: J.B. Lippincott Company; 1996.

22. US Department of Health and Human Services. Research-based web design \& usability guidelines. Washington, DC: US Government Printing Office, 2006. Available at: http://usability.gov/pdfs/guidelines_book.pdf. Accessed 2008 .
23. Bock BC, Graham AL, Sciamanna CN, et al. Smoking cessation treatment on the Internet: content, quality, and usability. Nicotine Tob Res. 2004;6: 207-219.

24. Hogarth S, Javitt G, Melzer D. The current landscape for direct-to-consumer genetic testing: legal, ethical, and policy issues. Annu Rev Genomics Hum Genet. 2008;9:161-182.

25. Liu Y, Pearson YE. Direct-to-consumer marketing of predictive medical genetic tests: assessment of current practices and policy recommendations. J Public Policy Marketing. 2008;27:131-148.

26. Berg C, Fryer-Edwards K. The ethical challenges of direct-to-consumer genetic testing. J Business Ethics. 2008;77:17-31.

27. Goddard KAB, Robitaille J, Dowling NF, et al. Health-related direct-toconsumer genetic tests: a public health assessment and analysis of practices related to internet-based tests for risk of thrombosis. Public Health Genomics. 2009;12:92-104.

28. Sterling R. The online promotion and sale of nutrigenomic services. Genet Med. 2008;10:784-796.

29. Genetics and Public Policy Center. Direct-to-consumer genetic testing companies. Available at: http://www.dnapolicy.org/resources/DTCcompanieslist. pdf. Accessed April 11, 2008.

30. Gollust SE, Wilfond BS, Hull SC. Direct-to-consumer sales of genetic services on the Internet. Genet Med. 2003;5:332-337.

31. Kaphingst KA, DeJong W, Rudd RE, Daltroy LH. A content analysis of direct-to-consumer television prescription drug advertisements. $J$ Health Commun. 2004;9:515-528.

32. McLaughlin G. SMOG grading - a new readability formula. J Read. 1969; 12:639-646

33. Fry E. A readability formula for short passages. J Read. 1990;33:594-597.

34. Janssens ACJW, Gwinn M, Bradley LA, Oostra BA, van Duijn CM, Khoury MJ. A critical appraisal of the scientific basis of commercial genomic profiles used to assess health risks and personalize health interventions. $A m J$ Hum Genet. 2008;82:593-599.

35. Ng PC, Murray SS, Levy S, Venter JC. An agenda for personalized medicine. Nature. 2009;461:724-726.

36. Evans JP, Green RC. Direct to consumer genetic testing: avoiding a culture war. Genet Med. 2009; 11:568-569.

37. Prainsack B, Reardon J. Misdirected precaution. Nature. 2008;456:34-35.

38. Shirts BH, Parker LS. Changing interpretations, stable genes: responsibilities of patients, professionals, and policy makers in the clinical interpretation of complex genetic information. Genet Med. 2008;10:778-783.

39. Mihaescu R, van Hoek M, Sijbrands E, et al. Evaluation of risk prediction updates from commercial genome-wide scans. Genet Med. 2009;11:588594.

40. Nielsen-Bohlman L, Panzer AM, Kindig DA, editors. Health literacy: a prescription to end confusion. Washington, DC: National Academies Press, 2004.

41. Birru M, Monaco V, Charles L, et al. Internet usage by low-literacy adults seeking health information: an observational analysis. $J$ Med Internet Res. 2004;6:e25.

42. Kaphingst KA, Zanfini C, Emmons KM. Accessibility of web sites containing colorectal cancer information to adults with limited literacy. Cancer Causes Control. 2006;17:147-151.

43. Gray S, O'Grady C, Karp L, et al. Risk information exposure and directto-consumer genetic testing for BRCA mutations among women with a personal or family history of breast or ovarian cancer. Cancer Epidemiol Biomarkers Prev. 2009;18:1303-1311.

44. Baylor-Henry M, Drezin NA. Regulation of prescription drug promotion: direct-to-consumer advertising. Clin Ther. 1998;20:C86-C95.

45. Javitt G, Katsanis S, Scott J, Hudson KL. Developing the blueprint for a genetic testing registry. Public Health Genomics. 2010;13:95-105. 